\title{
Preparation and characterization of flexible nanoliposomes loaded with daptomycin, a novel antibiotic, for topical skin therapy
}

This article was published in the following Dove Press journal:

International Journal of Nanomedicine

22 March 2013

Number of times this article has been viewed

\section{Chong Li \\ Xiaolin Zhang \\ Xinliang Huang \\ Xiaoying Wang \\ Guojian Liao \\ Zhangbao Chen}

College of Pharmaceutical Sciences, Southwest University, Chongqing,

People's Republic of China
Correspondence: Chong Li

College of Pharmaceutical Sciences,

Southwest University, 2 Tiansheng Road,

Chongqing 4007I6, People's Republic

of China

Tel $+86236825 \quad 1225$

Fax $+86236825 \quad 1225$

Email chongli2009@gmail.com
Abstract: The purpose of this study was to investigate flexible nanoliposomes for mediating topical delivery of daptomycin, and to document permeation rates and bacteriostatic activity towards skin infections. Response surface methodology was used to optimize the daptomycinloaded flexible nanoliposomes (DAP-FL), and the amount of drug loaded into the particles was evaluated as the investigation index. The optimal lipid ratio was lecithin to sodium cholate $17: 1(\mathrm{w} / \mathrm{w})$ and the lipid to drug ratio was $14: 1(\mathrm{w} / \mathrm{w})$. The hydration temperature was set at $37^{\circ} \mathrm{C}$ and the duration of treatment with ultrasound was 20 minutes. The DAP-FL obtained had a small mean particle size $(55.4 \mathrm{~nm})$ with a narrow size distribution (polydispersity index 0.15 ). The mean entrapment efficiency was $87.85 \% \pm 2.15 \%$ and the mean percent drug loading was $5.61 \% \pm 0.14 \%$. Using skin mounted between the donor and receptor compartments of a modified Franz diffusion cell, the percentage and quantity of cumulative daptomycin permeation from DAP-FL within 12 hours were measured at $96.28 \% \pm 0.70 \%$ and $(132.23 \pm 17.73)$ $\mu \mathrm{g} / \mathrm{cm}^{2} * 5=661.15 \pm 88.65 \mu \mathrm{g} / \mathrm{cm}^{2}$, directly, showing rapid and efficient antibacterial activity against Staphylococcus aureus. Following local administration of DAP-FL, daptomycin was detected in multilayer tissues within the skin and underlying structures in the dorsal skin of the mouse. Effective therapeutic concentrations were maintained for several hours, and significantly inhibited bacterial growth and injury-induced biofilms. These results demonstrate that the DAP-FL can enhance the ability of daptomycin to permeate the skin efficiently, where it has a powerful antibacterial action and activity against biofilms. This novel formulation of daptomycin has potential as a new approach in the clinical application of daptomycin.

Keywords: daptomycin, liposomes, response surface methodology, biofilm

\section{Introduction}

The development of new antibiotics to combat the crisis of antibiotic resistance to potentially life-threatening pathogens has attracted great attention over recent decades. ${ }^{1}$ Daptomycin, a novel cyclic lipopeptide antibacterial agent, has been used in the treatment of Gram-positive pathogens, including vancomycin-resistant enterococci and methicillin-resistant Staphylococcus aureus. Due to its unique chemical structure, which consists of a peptide nucleus with various lipid acyl groups at the $\mathrm{N}$ terminus characteristic of each component, daptomycin exerts its antibacterial effect via multiple mechanisms. ${ }^{2}$ It can disturb amino acid transport through the bacterial cell membrane, block synthesis of the bacterial cell wall, destroy the bacterial cell membrane which then releases its contents, and disrupt the membrane potential via surrounding calcium ions. ${ }^{3,4}$ Consequently, bacteria cannot easily become resistant to daptomycin. Cubicin ${ }^{\circledR}$ (daptomycin for injection, Cubist Pharmaceuticals Inc, Lexington, MA, USA) is the 
only approved once-daily treatment available for complex skin and skin structure infections caused by susceptible strains of Gram-positive micro-organisms and S. aureus bloodstream infections in the United States. Considering the patient compliance and drug distribution in the target tissues, there is a pressing need to develop new dosage formulations of daptomycin to satisfy a range of therapeutic requirements.

During recent decades, nanotechnology has become increasingly important in medicine because of its remarkable properties arising from the nanosize effect, and has shown superiority over traditional formulations for local topical therapy. For example, liposomes are a versatile drug nanocarrier, have been widely used in systemic therapy, and have shown potential for delivering drugs into multiple layers of the skin. ${ }^{5,6}$ The mechanism of enhanced skin delivery includes but is not limited to: the cell membrane-like structure of the liposome having good biocompatibility; the small size of liposomes; formation of drug reservoirs in the skin; and specific liposome-skin interactions. ${ }^{6,7} \mathrm{Cevc}$ et al have introduced a further step to create flexible liposomes and transfersomes containing lecithin and cholesterol. ${ }^{8,9}$ Surface-active agents can be inserted into the lipid bilayers of flexible liposomes and create a "softened" bilayer membrane, thus making liposomes more flexible and permeable than ordinary liposomes. ${ }^{10-12}$ The highly deformable membranes of flexible liposomes facilitate their rapid distribution into the skin. Further, the osmotic gradient created by the difference in water concentration between the surface and interior of the skin has been identified as the major driving force for penetration of flexible liposomes into the skin. ${ }^{8}$

This study developed daptomycin-loaded flexible nanoliposomes (DAP-FL) for topical skin therapy. The formulation was optimized via response surface methodology. The physicochemical properties of the optimized DAP-FL were characterized, and their bioactivity against $S$. aureus and biofilms was evaluated both in vitro and in vivo. Our results demonstrate the potential of DAP-FL in the treatment of complicated skin and skin structure infections caused by susceptible strains of designated micro-organisms.

\section{Materials and methods Materials}

Daptomycin (purity $>98 \%$ ) was sourced from Melone Pharmaceutical Co (Dalian, People's Republic of China), soy lecithin (purity $>98 \%$ ) from Aladdin Asia (Shanghai, People's Republic of China), and sodium cholate (purity $>98 \%$ ) from TCI Chemical Reagent Co, Ltd (Tokyo, Japan). Methyl alco- hol and acetonitrile (high-pressure liquid chromatography grade) were obtained from Swell Scientific Instruments Co, Ltd., Chengdu, People's Republic of China. All reagents were of analytical grade and used without further purification. The isotonic phosphate-buffered solution used in this study contained $8.01 \mathrm{~g} / \mathrm{L} \mathrm{NaCl}, 0.2 \mathrm{~g} / \mathrm{L} \mathrm{KCl}, 1.78 \mathrm{~g} / \mathrm{L}$ $\mathrm{Na}_{2} \mathrm{HPO}_{4} \cdot 2 \mathrm{H}_{2} \mathrm{O}$, and $0.27 \mathrm{~g} / \mathrm{L} \mathrm{KH}_{2} \mathrm{PO}_{4}$. The $\mathrm{pH}$ value was adjusted to $7.4 \pm 0.1$.

S. aureus (ATCC25923) was incubated in tryptic soy broth (Nissui Pharmaceuticals, Tokyo, Japan) at $37^{\circ} \mathrm{C} .{ }^{13}$ Six-week-old male BALB/c mice weighing approximately $20 \pm 2 \mathrm{~g}$ were used in this study, and the mice were raised under specific pathogen-free conditions. All animal experiments were carried out in accordance with the guidelines for animal experiments performed at Southwest University (Chongqing, People's Republic of China).

\section{Preparation of DAP-FL}

DAP-FL were prepared using a dry film dispersion method. Briefly, soy phosphatidylcholine $(264.50 \mathrm{mg})$ and sodium cholate $(15.50 \mathrm{mg})$ were dissolved in $8 \mathrm{~mL}$ of chloroform/ methanol $(1 / 3, v / v)$ solution and rotary evaporated to form a thin film at $37^{\circ} \mathrm{C}$. After complete removal of the organic solvent, $10 \mathrm{~mL}$ of phosphate-buffered solution ( $\mathrm{pH} 7.4$ ) containing $20 \mathrm{mg}$ of daptomycin was added to the lipid film as a hydration solution and shaken in a water bath at $150 \mathrm{rpm}$ for one hour. The processing temperature was maintained at $37^{\circ} \mathrm{C}$. The suspensions obtained were then sonicated at $800 \mathrm{~W}$ (intermittent operation for 10 seconds on and 10 seconds off) for 20 minutes to obtain small and uniform liposome vesicles.

\section{Characterization of DAP-FL}

The mean particle size, polydispersity index, and zeta potential of the liposome vesicles were determined using dynamic light scattering (Zetasizer Nano ZS, Malvern, Worcestershire, $\mathrm{UK}$ ) at $25^{\circ} \mathrm{C}$. Before characterization, the samples were further diluted with phosphate-buffered solution to form a liposome suspension with a total lipid concentration of $5 \mathrm{mg} / \mathrm{mL}$. Transmission electron microscopy was used to characterize the morphology of the liposome vesicles using a negative staining method. Samples were pretreated with $2 \%$ phosphotungstic acid and then air-dried before measurement.

\section{Encapsulation efficiency and drug-loading of daptomycin}

The percentage of daptomycin encapsulated in the flexible liposomes was measured in two steps. First, the DAPFL obtained before chromatographic purification were 
divided into two equal parts. One part was dialyzed against phosphate-buffered solution overnight, using a dialysis membrane with a molecular cutoff of approximately 10,000 Da. The other part was diluted in the same volume as the first sample. The two samples were then lysed with $0.1 \%(\mathrm{v} / \mathrm{v})$ Triton X-100, and the daptomycin content was determined using high-pressure liquid chromatography. The entrapment efficiency of DAP-FL ( $E_{\text {DAP-FL }}, \%$ ) was calculated as:

$$
\mathrm{EE}_{\text {DAP-FL }}(\%)=\mathrm{W} / \mathrm{W}_{0} \times 100
$$

where $\mathrm{W}$ and $\mathrm{W}_{0}$ are the daptomycin content in the purified flexible liposomes and the total drug content in the dispersion, respectively.

Percent drug loading in the prepared liposomes $\left(\mathrm{PDL}_{\mathrm{DAP}-\mathrm{FL}} \%\right)$ was calculated as:

$$
\mathrm{PDL}_{\text {DAP-FL }} \%=\mathrm{W} /\left(\mathrm{W}+\mathrm{W}_{\mathrm{e}}\right) \times 100
$$

where $\mathrm{W}$ is the daptomycin content in purified flexible liposomes and $\mathrm{W}_{\mathrm{e}}$ is the total amount of excipients.

Quantification of daptomycin was done using a reverse phase high-pressure liquid chromatography system with an ultraviolet absorbance detector set at $223 \mathrm{~nm}$. The mobile phase consisted of $0.2 \mathrm{M}$ phosphate buffer ( $\mathrm{pH} 5.5$ )/ acetonitrile $(64 / 36, \mathrm{v} / \mathrm{v})$. A C18 chromatographic column $(150 \mathrm{~mm} \times 4.6 \mathrm{~mm}, 5 \mu \mathrm{m})$ was used, with the flow rate set at $0.7 \mathrm{~mL}$ per minute at $30^{\circ} \mathrm{C} .^{14,15}$

\section{DAP-FL stability study}

The DAP-FL were stored as native dispersions at $4{ }^{\circ} \mathrm{C}$ in a refrigerator. Changes in particle size and polydispersity were determined, and the method used for detection of the leakage rate was similar to that used for determination of encapsulation efficiency as described above.

\section{In vitro skin permeation study}

Mouse skin was used as a model membrane for human skin during the permeation studies. Dorsal mouse skin was treated to remove any fatty material, then mounted between the donor and receptor compartments of a modified Franz diffusion cell, with the epidermal side facing the donor compartment. ${ }^{16,17}$ The effective diffusion area was $2.50 \mathrm{~cm}^{2}$, and the volume of the receptor compartment was $50 \mathrm{~mL}$. The receptor compartment was filled with $50 \mathrm{~mL}$ of phosphate-buffered solution maintained at $37^{\circ} \mathrm{C} \pm 0.5^{\circ} \mathrm{C}$ and stirred at $100 \mathrm{rpm}$. One $\mathrm{mL}$ of DAP-FL was placed into the donor compartment, and the top of the diffusion cell was covered. At predetermined time intervals $(0.5,1,2,4,6,8,12$, and 24 hours $)$, one $\mathrm{mL}$ of receptor medium was withdrawn and replenished with one $\mathrm{mL}$ of fresh medium. The concentration of daptomycin was analyzed by high-pressure liquid chromatography, and the cumulative amount of daptomycin permeated was plotted against time.

\section{In vitro pharmacodynamic study}

The antibacterial activity of the daptomycin formulation after permeation into the skin was evaluated first in vitro. The same device with the modified Franz diffusion cell described above was used, varying the point at which bacteria or a biofilm of $S$. aureus was added to the receptor compartment.

Briefly, S. aureus was inoculated into culture and grown for 8 hours until the bacteria reached the stationary phase. One $\mathrm{mL}$ of bacterial suspension was withdrawn, and bacteria were recovered from the culture using centrifugation. $S$. aureus bacteria were then added into the receptor compartment of the Franz diffusion cell. The number of bacteria in the samples withdrawn from the receptor medium at predetermined time intervals was quantified by counting colony-forming units.

For the antibiofilm assay, S. aureus bacteria were inoculated in tryptic soy broth (with $1 \mathrm{~cm}^{2}$ pieces of silicone membrane) culture and grown for 7 days to form mature biofilms of $S$. aureus bacteria on the silicone membranes. ${ }^{13}$ One piece of mature biofilm was placed into the Franz diffusion cell with $50 \mathrm{~mL}$ of phosphate-buffered solution and maintained at $37^{\circ} \mathrm{C} \pm 0.5^{\circ} \mathrm{C}$. After 24 hours, the silicone membrane was removed and the shape of the biofilms on the membrane was observed using scanning electron microscopy. ${ }^{18}$ The bacterial count was quantified by counting the number of colony-forming units per piece of membrane after shaking S. aureus from the biofilms using sonication. ${ }^{19}$

\section{Pharmacokinetic study in vivo}

The mice were lightly anesthetized using pentobarbitone ( $35 \mathrm{mg} / \mathrm{kg}$ intraperitoneally with additional boluses as needed to maintain anesthesia). Hair from a $4 \mathrm{~cm}^{2}$ dorsal area was removed using electric clippers and the rest of the hair was eliminated using 4\% sodium sulfide solution followed by cleaning with phosphate buffer. DAP-FL (containing daptomycin $50 \mathrm{mg} / \mathrm{kg}$ ) was administered to the dorsal area. After administration, samples of the dermis, subcutaneous tissue, fascia, superficial muscle, and deep muscle were collected at predetermined time intervals, and weighed and stored in a cool place. The samples were then homogenized in phosphate buffer and centrifuged. The resulting supernatants from the tissue samples were treated with acetonitrile to precipitate the 
proteins. After centrifugation, the supernatants were concentrated using a pressure-blowing concentrator and analyzed using high-pressure liquid chromatography. The data are expressed as mean \pm standard deviation $(n=5)$.

\section{Pharmacodynamic study in vivo}

The mice were anesthetized using pentobarbitone. Hair on a $4 \mathrm{~cm}^{2}$ dorsal area was shaved and the skin was cleaned with phosphate buffer. One subcutaneous pocket was made on each side of the median line by a $1.2 \mathrm{~cm}$ incision. Prior to implantation, a silicone membrane $\left(1 \mathrm{~cm}^{2}\right)$ was kept in tryptic soy broth within the $S$. aureus culture for 7 days to form the mature biofilms, and the silicone membranes were then implanted into the pockets ${ }^{20}$ (Figure 1). One day after implantation, the mice were randomly divided into three groups and treated with saline solution (blank control group), daptomycin solution at $50 \mathrm{mg} / \mathrm{kg}$ (positive control group), and DAP-FL at $50 \mathrm{mg} / \mathrm{kg}$ (experimental group). The silicone membranes were retrieved 4 days after administration and imaged by scanning electron microscopy. The number of colony-forming units per silicone membrane was quantified by counting after shaking $S$. aureus from the biofilms ultrasonically.

\section{Results}

\section{Preparation and optimization of DAP-FL}

Three possible factors were found to influence the preparation and quality of the daptomycin formulation in the preliminary studies. To obtain optimal levels of these variables and obtain the best system performance simultaneously, response surface methodology was used to optimize the most important parameters involved in the preparation of DAPFL. Design Expert version 8.1 software was used to design
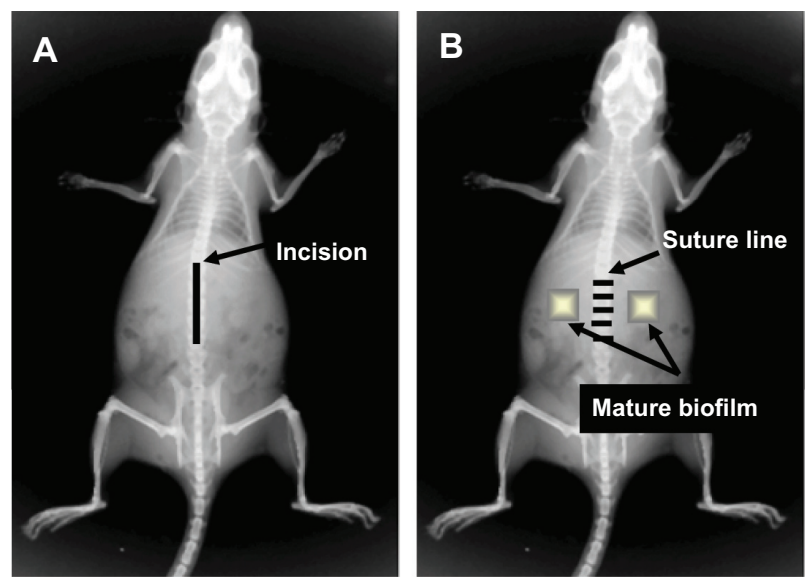

Figure I Method for biofilm implantation on the back of the mouse model. the experimental groups and analyze the study results. Drug loading was used as the evaluation index.

The study results were fitted to a full second-order model, and the following equation was obtained:

$$
\begin{aligned}
\mathrm{Y}= & 7.51-0.41 \mathrm{~A}+0.72 \mathrm{~B}+0.56 \mathrm{C}-0.26 \mathrm{AB}+0.33 \mathrm{BC} \\
& -0.98 \mathrm{~A}^{2}-1.31 \mathrm{~B}^{2}-2.15 \mathrm{C}^{2}
\end{aligned}
$$

where A (lecithin to sodium cholate ratio), B (lipid to drug ratio), $\mathrm{C}$ (time of ultrasonic treatment), $\mathrm{AB}, \mathrm{AC}, \mathrm{A}^{2}, \mathrm{~B}^{2}$, and $\mathrm{C}^{2}$ were significant model terms. A Pred R (predeterminated relative coefficient) - squared of 0.8826 is in reasonable agreement with the Adj R (Adjusted relative coefficient) - squared of 0.9770. An adequate precision of 24.316 indicates an adequate signal to noise ratio. Therefore, the model obtained is credible and could be used to navigate the design space and for practical predictions. Figure 2 provides a visual representation of the effect of interactions between critical factors on drug loading. The optimal preparation conditions for DAP-FL were identified as a lecithin to sodium cholate ratio of 17:1 (w/w), a lipid to drug ratio of $14: 1(\mathrm{w} / \mathrm{w})$, and treatment with ultrasound for 20 minutes.

\section{Characterization of DAP-FL}

The mean vesicle diameter was $55.4 \mathrm{~nm}$ (Figure 3) and the zeta potential was $-15.1 \mathrm{mV}$. Mean entrapment efficiency was $87.85 \% \pm 2.15 \%$, and the percentage drug loading was $5.61 \% \pm 0.14 \%$. Importantly, DAP-FL vesicle size and size distribution remained almost unchanged, and no obvious daptomycin leakage occurred after storage at $4^{\circ} \mathrm{C}$ in a refrigerator for 2 months (Table 1), indicating that the formulation has good stability. For high-pressure liquid chromatographic detection of daptomycin in the formulation, the calibration curve was $y=10347 x-42667$, which was linear over a concentration range of $0.03-4.00 \mu \mathrm{g} / \mathrm{mL}$ and had a correlation coefficient $>0.999$.

\section{Skin permeation study in vitro}

As shown in Figure 4, the cumulative percentage of daptomycin permeated through the skin was greater than $25 \%$ within the first 2 hours $(37.35 \% \pm 3.02 \%)$, and the cumulative amount of daptomycin permeated through the skin was $(51.72 \pm 9.37) \mu \mathrm{g} / \mathrm{cm}^{2} * 5=258.6 \pm 46.85 \mu \mathrm{g} / \mathrm{cm}^{2}$ directly. After 12 hours, almost all of the daptomycin had penetrated through the skin, with a cumulative percentage of $96.28 \% \pm 0.70 \%$ and a quantity of $(132.23 \pm 17.73) \mu \mathrm{g} / \mathrm{cm}^{2}$ $* 5=661.15 \pm 88.65 \mu \mathrm{g} / \mathrm{cm}^{2}$ directly. These results were further analyzed using Drug and Statistics Software version 3.0 (Mathematical Pharmacology Professional Committee of 


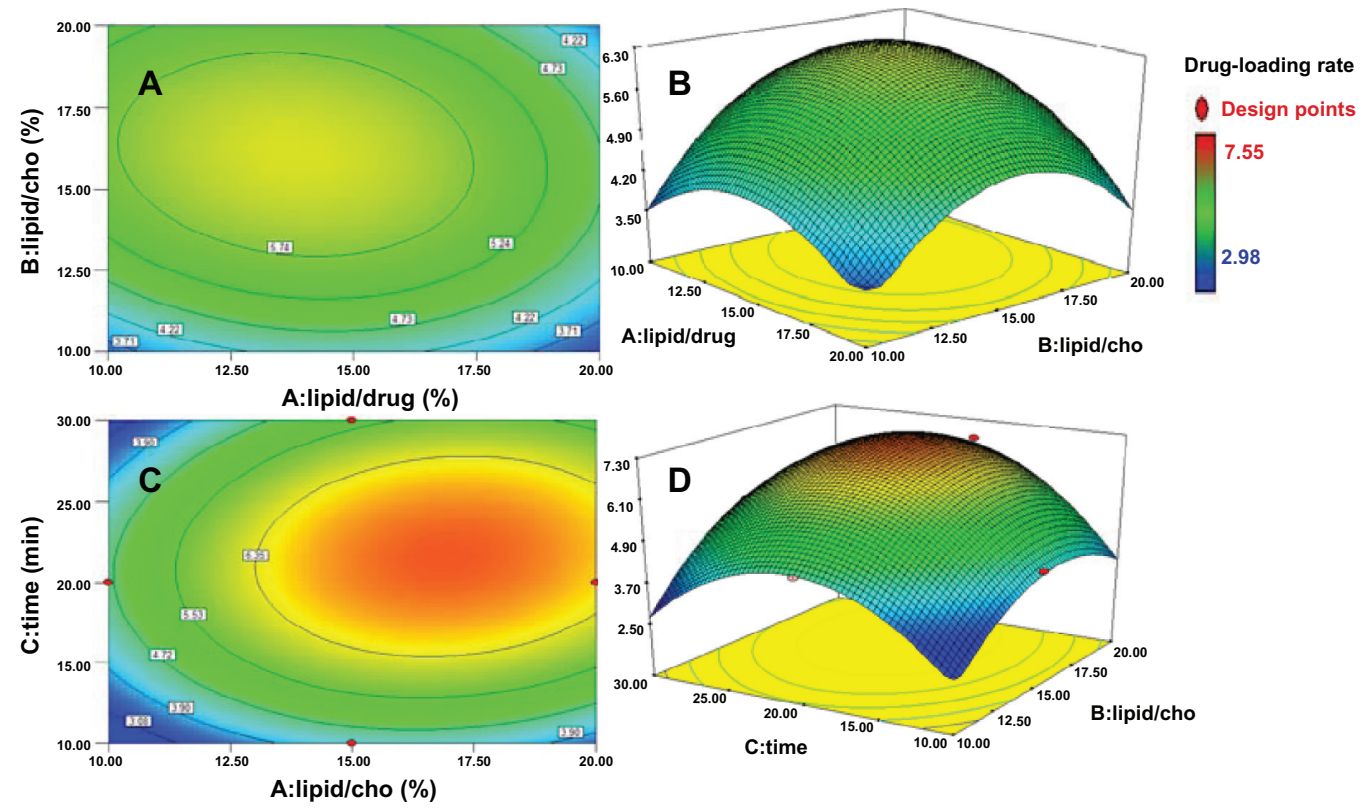

Figure 2 Three-dimensional models of the response surface for optimization of daptomycin-loaded flexible liposomes. (A) Effects of lipid/drug and lipid/sodium cholate on drug loading; (B) three-dimensional model of effects of lipid/drug and lipid/sodium cholate on drug loading; (C) effects of lipid/drug and duration of sonication treatment on drug loading; (D) three-dimensional model of effects of lipid/drug and duration of sonication treatment on drug loading.

China), fitted to a quadratic model, and the following expression was obtained:

$$
\mathrm{Y}=0.211+0.191 \mathrm{~T}-0.005 \mathrm{~T}^{\wedge} 2
$$

where $\mathrm{T}$ is time and $\mathrm{Y}$ is quantity of cumulative permeation at time $\mathrm{T}(\mathrm{r}=0.994)$.

\section{Pharmacodynamic study in vitro}

The spread-plate method (with a dilution rate of 10) was conducted to count the number of $S$. aureus bacteria at each time point for the experimental and control groups. As shown in Figure 5, DAP-FL had a remarkable bacteriostatic effect compared with the control group. The possible effect of DAP-FL on biofilms after transdermal flux was also investigated. The biofilms were observed by scanning electron microscopy, which gives very clear images. The number of $S$. aureus cells embedded in the biofilms was counted after ultrasonic shaking. Damaged
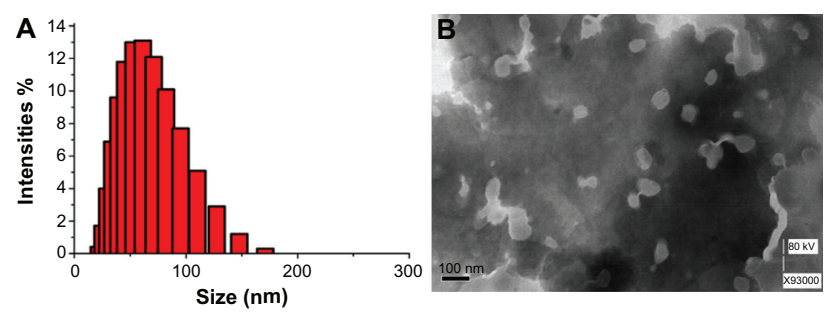

Figure 3 Determination of daptomycin-loaded flexible liposomes by dynamic light scattering $(\mathbf{A})$ and transmission electron microscopy (B).
S. aureus biofilms were observed in the experimental group with broken pieces scattered on the silicone membrane, whereas the biofilms in the control group were unaffected. Very few viable $S$. aureus cells were observed in the experimental group, while the populations of $S$. aureus in the control group reached a $10^{8}$ order of magnitude (Figure 5A).

\section{Pharmacokinetic study in vivo}

Figure 6 shows the distribution of daptomycin in different layers of mouse skin tissue and structures on the dorsal area, including the maximum concentrations of daptomycin reached within 2 hours for all five skin layers. For the dermis and subcutaneous tissues, the maximum concentrations were $194.55 \pm 12.48 \mu \mathrm{g} / \mathrm{g}$ ( $4.86 \%$ of total dose) and $175.30 \pm 11.54 \mu \mathrm{g} / \mathrm{g}(4.61 \%$ of total dose), respectively. The daptomycin concentration in these two layers was maintained at over $40 \mu \mathrm{g} / \mathrm{g}$ for 12 hours. In deep muscles, the maximum concentration reached more than $100 \mu \mathrm{g} / \mathrm{g}(100.40 \pm 9.54 \mu \mathrm{g} / \mathrm{g})$ and remained above a concen-

Table I Characterization of stability of daptomycin-loaded flexible liposomes

\begin{tabular}{llll}
\hline Time & Size $(\mathbf{n m})$ & PDI & DAP leakage $\mathbf{( \% )}$ \\
\hline 0 day & 55.40 & 0.150 & - \\
30 days & 56.66 & 0.167 & $0.57 \pm 0.15$ \\
60 days & 58.76 & 0.173 & $1.73 \pm 0.24$ \\
\hline
\end{tabular}

Note: Data are shown as the mean \pm standard deviation $(n=3)$. Abbreviations: DAP, daptomycin; PDI, polydispersity index. 

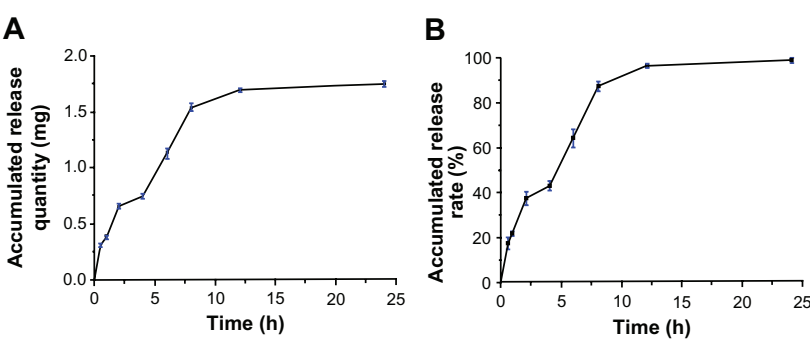

Figure 4 Cumulative in vitro permeation of daptomycin-loaded flexible liposomes. (A) Quantity of cumulative permeation and (B) percentage of cumulative permeation of daptomycin from daptomycin-loaded flexible liposomes.

Note: Data are presented as the mean \pm standard deviation $(n=3)$.

tration of $40 \mu \mathrm{g} / \mathrm{g}$ for more than 6 hours. Considering the high potency of daptomycin against $S$. aureus (minimum inhibitory concentration $0.25-0.50 \mu \mathrm{g} / \mathrm{mL}),{ }^{21}$ the amounts of permeated and accumulated drug were theoretically sufficient to inhibit the growth of pathogenic bacteria. The main pharmacokinetic parameters were then calculated using noncompartmental analysis (Drug and Statistics Software version 3.0) as shown in Table 2.

\section{Pharmacodynamic study in vivo}

As expected, the same pharmacodynamic trends were observed in vivo as in vitro. We also observed the shape of the biofilms and counted the number of viable $S$. aureus bacteria in these biofilms using scanning electron microscopy and the spread-plate method, respectively. The results are shown in Figure 7. On day 4 following administration, the biofilm

A
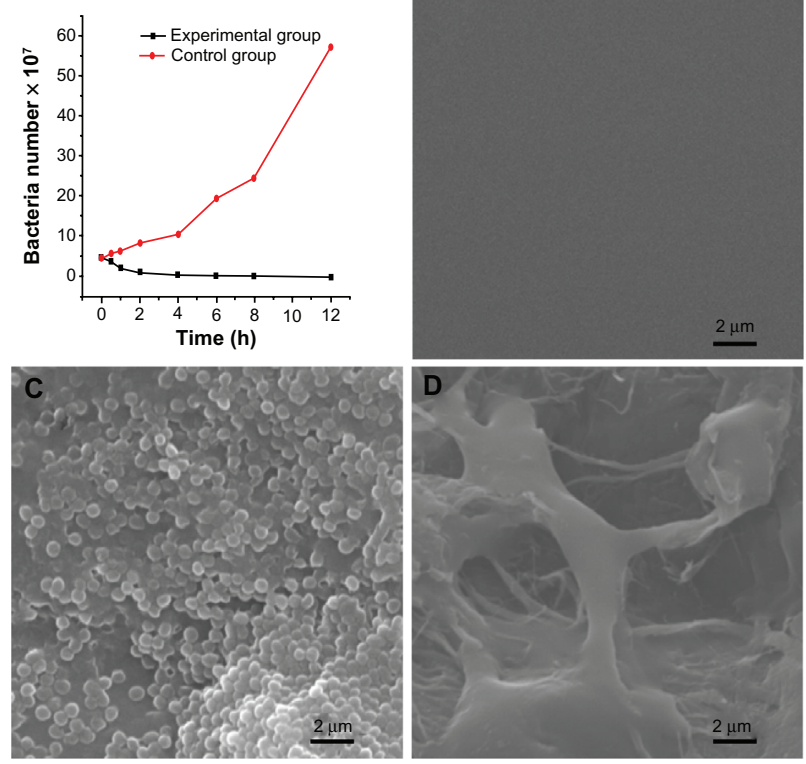

Figure 5 Bacteriostatic effect of daptomycin-loaded flexible liposomes in vitro. (A) Inhibition of pathogen growth by daptomycin-loaded flexible liposomes; (B) scanning electron micrographs of silicone membrane; (C) scanning electron micrographs for the blank control; and (D) scanning electron micrographs for the experimental group.
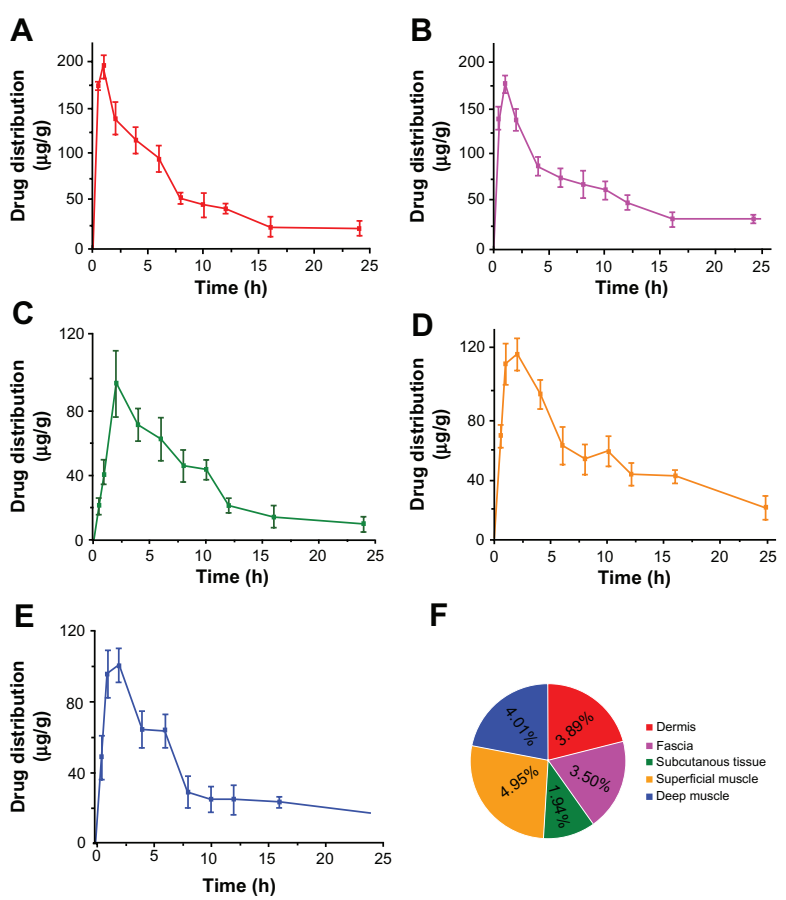

$\mathbf{F}$

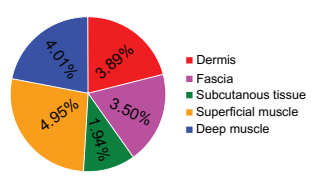

Figure 6 Pharmacodynamic study of skin and underlying structures. (A) Distribution of daptomycin in dermis;(B) subcutaneous distribution of daptomycin;(C) distribution of daptomycin in fascia; (D) distribution of daptomycin in superficial muscle; (E) distribution of daptomycin in deep muscle; and (F) percentage of drug accumulated in each layer of skin tissue and structures at time of peak concentration. Note: Data are presented as the mean \pm standard deviation $(n=5)$.

surfaces in the blank control group were thickly dotted with viable $S$. aureus, while both the experimental group and the positive control group showed only scattered $S$. aureus on damaged biofilms. When counting cell numbers, there was no significant difference $(P>0.05)$ between the experimental group (transdermal delivery by flexible nanoliposomes) and the positive control group (intravenous injection).

\section{Discussion}

In recent decades, multidrug-resistant bacteria have posed a serious challenge to development of new antibiotic agents. Accordingly, there is an urgent need to identify new drug resistance mechanisms as part of research and development concerning novel antibiotic molecular entities. Due to its unique functional mechanism, daptomycin is currently considered to be a promising agent for the treatment of Gram-positive infections. ${ }^{22}$ Cubicin, a daptomycin solution for injection, has been used clinically. However, with respect to the detailed requirements for specific diseases and syndromes, an appropriate route of administration and vehicle for drug delivery are needed, to enhance accumulation of the drug further in target tissues and to improve the outcome of antibacterial treatment. Therefore, development of novel formulations for daptomycin may expand its range of applications, with potential clinical 
Table 2 Main pharmacokinetic parameters for daptomycin-loaded flexible liposomes after topical administration

\begin{tabular}{|c|c|c|c|c|c|c|}
\hline Parameters & Unit & Dermis & Fascia & Subcutaneous tissue & Superficial muscle & Deep muscle \\
\hline$A \cup C(0-t)$ & $\mu g / g * h$ & 1353.013 & 751.85 & 1391.725 & 1262.718 & 803.993 \\
\hline $\operatorname{A\cup C}(0-\infty)$ & $\mu g / g^{*} h$ & 1722.585 & 759.564 & $150 \mid .103$ & 1552.265 & 1252.495 \\
\hline $\operatorname{AUMC}(0-t)$ & $\mathrm{h}^{*} \mathrm{~h} * \mu \mathrm{g} / \mathrm{g}$ & 9732.3 & 5368.513 & 11592.013 & 11162.815 & 6371.033 \\
\hline $\operatorname{AUMC}(0-\infty)$ & $\mathrm{h} * \mathrm{~h} * \mu \mathrm{g} / \mathrm{g}$ & 25170.76 & 5588.706 & 15190.447 & 22087.614 & 31735.801 \\
\hline $\operatorname{MRT}(0-t)$ & $\mathrm{h}$ & 7.193 & 7.14 & 8.329 & 8.84 & 7.924 \\
\hline $\operatorname{MRT}(0-\infty)$ & $\mathrm{h}$ & 14.612 & 7.358 & 10.12 & 14.229 & 25.338 \\
\hline$\lambda z$ & $\mathrm{I} / \mathrm{h}$ & 0.056 & 0.22 & 0.112 & 0.073 & 0.031 \\
\hline $\mathrm{tl} / 2$ & $\mathrm{~h}$ & 12.317 & 3.15 & 6.167 & 9.515 & 22.56 \\
\hline$C \max$ & $\mu g / g$ & 190.55 & 95.2 & 170.2 & 120.7 & 95.4 \\
\hline
\end{tabular}

Abbreviations: $\mathrm{t}_{1 / 2}$, biological half life; AUC, area under Concentration-time curve; AUMC, area under the first moment of the plasma concentration-time curve. MRT, Mean Retention Time; $\mathrm{t}_{1 / 2}$, biological half life; $\mathrm{C}_{\max }$, maximum concentration.

significance. Effective drug permeation and local distribution are important in the treatment of topical skin infections. Flexible nanoliposomes can adapt to the environment and diffuse effectively through the skin and underlying tissues.

In the present study, optimized DAP-FL had a particle small size with a narrow size distribution, and could achieve high drug loading with excellent stability. The in vitro skin permeation study indicated that flexible nanoliposomes can diffuse rapidly and efficiently into the skin and inhibit pathogen growth significantly in a simulated receptor compartment. Further, pharmacokinetic data gathered from tissues suggest that DAP-FL can permeate the skin and underlying tissues, reaching a maximum concentration rapidly and maintaining high drug levels for several hours (compared with the high potency of daptomycin against
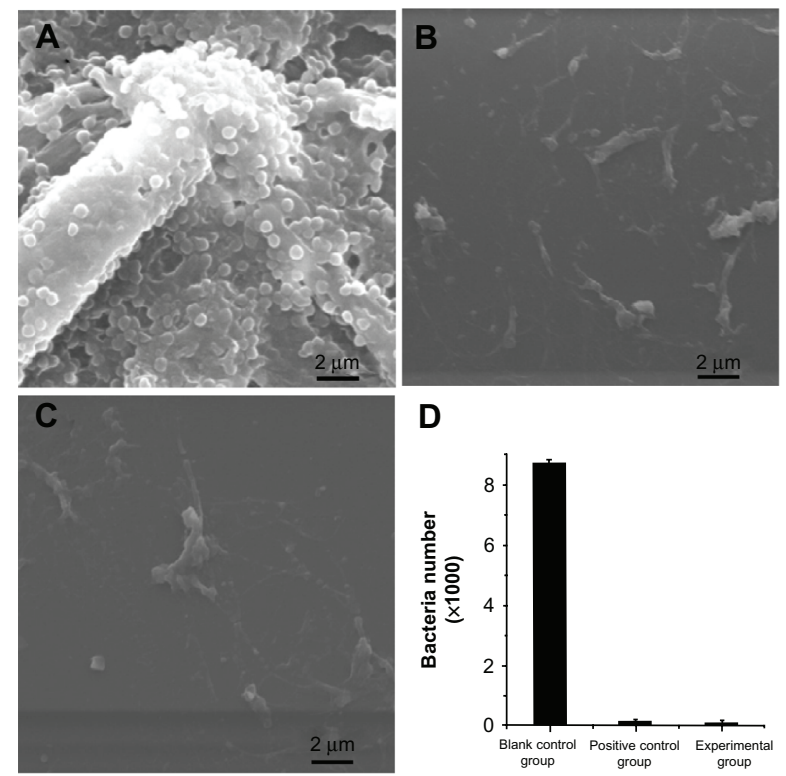

Figure 7 Pharmacodynamic study in vivo on day 4 following administration. (A) Scanning electron micrographs of blank control group; (B) scanning electron micrographs of positive control group; (C) scanning electron micrographs of experimental group; and (D) number of viable Staphylococcus aureus bacteria remaining in each treatment group. pathogens). The dose of daptomycin used in this study was based on the medical directions for Cubicin, which set the dose at $4 \mathrm{mg} / \mathrm{kg}$ for treatment of complicated skin and skin structure infections in humans; we then converted the human dose to an equivalent mouse dose. This algorithm, based on bioequivalence between humans and mice, was devised by Reagan-Shaw et al. ${ }^{23}$ It was concluded that the human dose $(\mathrm{mg} / \mathrm{kg})$ was equivalent to the animal dose $(\mathrm{mg} / \mathrm{kg})$ multiplied by the animal $\mathrm{K}_{m}$ /human $\mathrm{K}_{m}$, where the human $\mathrm{K}_{m}=37$ and the mouse $\mathrm{K}_{m}=3$. Accordingly, the mouse $\mathrm{K}_{m}(\mathrm{mg} / \mathrm{kg})$ of daptomycin $=4 \mathrm{mg} / \mathrm{kg} \times 37 / 3 \approx 50 \mathrm{mg} / \mathrm{kg}$.

In the clinical setting, many antibiotic drugs sterilize incompletely because of the presence of biofilm which is an aggregate of bacteria in which cells adhere to inactive objects or living surfaces. ${ }^{24,25}$ These adherent bacteria have a certain structure and can be protected by a self-produced matrix of extracellular polymeric substances. Once a bacterium forms a mature biofilm, it can resist host immunity and sterilization by antibiotic agents. ${ }^{24}$ Daptomycin can be used for the treatment of biofilm, where transdermal flux of DAP-FL shows potent bacteriostatic activity, demonstrated by both in vitro and in vivo studies. Considering the interactions between liposomal lipid bilayers and natural biomembranes, it is expected that flexible nanoliposomes may enable greater penetration of antibacterial agents into biofilm. ${ }^{26}$

In conclusion, novel DAP-FL were prepared, which can diffuse efficiently into skin and show both anti-infective and antibiofilm activity against specific pathogens within the skin and underlying structures. Thus, our research may provide useful information for potential clinical applications using daptomycin as an alternative delivery approach to current intravenous administration.

\section{Acknowledgments}

The authors are grateful for the financial support of the National Creating New Drug Program of China (2010 ZX 09401-306-1-4), 
the special fund of the Chongqing Key Laboratory, Foundation for University Key Teachers by the Chongqing Municipal Education Commission, the Fundamental Research Funds for Central Universities (XDJK2013A010), and the doctoral fund of Southwest University (SWU110028).

\section{Disclosure}

The authors report no conflicts of interest in this work.

\section{References}

1. Kirkpatrick P, Raja A, LaBonte J, Lebbos J. Daptomycin. Nat Rev Drug Discov. 2003;2:943-944.

2. Kirsch LE, Molloy RM, Debono M, et al. Kinetics of the aspartyl transpeptidation of daptomycin, a novel lipopeptide antibiotic. Pharm Res. 1989;6:387-393.

3. Patel D, Husain M, Vidaillac C, et al. Mechanisms of in vitro-selected daptomycin - non-susceptibility in Staphylococcus aureus. Int $J$ Antimicrob Agents. 2011;38:442-446.

4. Alborn WE, Allen NE, Preston DA. Daptomycin disrupts membrane potential in growing Staphyococcus aureus. Antimicrob Agents Chemother. 1991;35:2282-2287.

5. Foldvari M, Gesztes A, Mezei M. Dermal drug delivery by liposome encapsulation: clinical and electron microscopic studies. Arch Dermatol Res. 1990;7:479-489.

6. Verma DD, Verma S, Blume G, et al. Liposomes increase skin penetration of entrapped and non-entrapped hydrophilic substances into human skin: a skin penetration and confocal laser scanning microscopy study. Eur J Pharm Biopharm. 2003;55:271-277.

7. Verma DD, Verma S, Blume G, et al. Particle size of liposomes influences dermal delivery of substances into skin. Int J Pharm. 2003;258: 141-151.

8. Cerc G, Blume G. Lipid vesicles penetrate into intact skin owing to the transdermal osmotic gradients and hydration force. Biochim Biophys Acta. 1992;1104:226-232.

9. Cevc G, Schatzlein A, Richardsen H. Ultradeformable lipid vesicles can penetrate the skin and other semi-permeable barriers unfragmented. Evidence from double label CLSM experiments and direct size measurements. Biochim Biophys Acta. 2002;1564:21-30.

10. Cevc G, Blume G, Schatzlein A. Transfersome-mediated transepidermal delivery improves the regio-specificity and biological activity of corticosteroids in vivo. J Control Release. 1997;45:211-226.
11. Cevc G, Blume G. New, highly efficient formulation of diclofenac for the topical, transdermal administration in ultradeformable drug carriers, transfersomes. Biochim Biophys Acta. 2001;1514:191-205.

12. Singodia D, Gupta GK, Verma A, et al. Development and performance evaluation of amphotericin B transfersomes against resistant and sensitive clinical isolates of visceral leishmaniasis. J Biomed Nanotechnol. 2010;6:293-302.

13. Masako K, Hideyuki I, Shigeyuki O, et al. A novel method to control the balance of skin mecroflora. Part 1. Attack biofilm of Staphylococcus aureus without antibiotics. J Dermatol Sci. 2005;38:197-205.

14. Tobin CM, Darville JM, Lovering AM, et al. An HPLC assay for daptomycin in serum. J Antimicrob Chemother. 2008;62:1462-1476.

15. Verdier MC, Bentue-Ferrer D, Tribut O, et al. Determination of daptomycin in human plasma by liquid chromatography-tandem mass spectrometry. Clinical application. Clin Chem Lab Med. 2011;49:69-75.

16. Nayak AK, Mohanty B, Sen KK. Comparative evaluation of in vitro diclofenac sodium permeability across excised mouse skin from different common pharmaceutical vehicles. International Journal of Pharm Tech Research. 2010;2:920-930.

17. Duangjit S, Opanasopit P, Rojanarata T, Ngawhirunpat T. Characterization and in vitro skin permeation of meloxicam-loaded liposomes versus transfersomes. J Drug Deliv. 2011;2011:418316.

18. Schinabeck MK, Long LA, Hossain MA, et al. Rabbit model of Candida albicans biofilm infection: liposomal amphotericin B antifungal lock therapy. Antimicrob Agents Chemother. 2004;48:1727-1732.

19. Chicurel M. Slimebusters. Nature. 2000;408:284-286.

20. Ghiselli R, Giacometti A, Goffi L, et al. Prophylaxis against Staphylococcus aureus vascular graft infection with mupirocin-soaked, collagensealed dacron. J Surg Res. 2001;99:316-320.

21. Sader HS, Jones RN. Antimicrobial susceptibility of Gram-positive bacteria from US medical centers: results of the Daptomycin Surveillance Program (2007-2008). Diagn Microbiol Infect Dis. 2009;65: $158-162$.

22. Lambert WJ. Drug delivery: what the future holds. Bio Pharm Int. 2007;20:32-39.

23. Reagan-Shaw S, Nihal M, Ahmad N. Dose translation from animal to human studies revisited. FASEB J. 2007;22:659-661.

24. Fux CA, Stoodley P, Hall-Stoodley L, Costerton JW. Bacterial biofilms: a diagnostic and therapeutic challenge. Expert Rev Anti Infect Ther. 2003;1:667-683.

25. Roveta S, Marchese A, Schito GC. Activity of daptomycin on biofilms produced on a plastic support by Staphylococcus spp. Int J Antimicrob Agents. 2008;31:321-328.

26. Jones MN. Use of liposomes to delivery bactericides to bacterial biofilms. Methods Enzymol. 2005;391:211-228.
International Journal of Nanomedicine

\section{Publish your work in this journal}

The International Journal of Nanomedicine is an international, peerreviewed journal focusing on the application of nanotechnology in diagnostics, therapeutics, and drug delivery systems throughout the biomedical field. This journal is indexed on PubMed Central, MedLine, CAS, SciSearch $\AA$, Current Contents $\AA /$ Clinical Medicine,

\section{Dovepress}

Journal Citation Reports/Science Edition, EMBase, Scopus and the Elsevier Bibliographic databases. The manuscript management system is completely online and includes a very quick and fair peer-review system, which is all easy to use. Visit http://www.dovepress.com/ testimonials.php to read real quotes from published authors. 